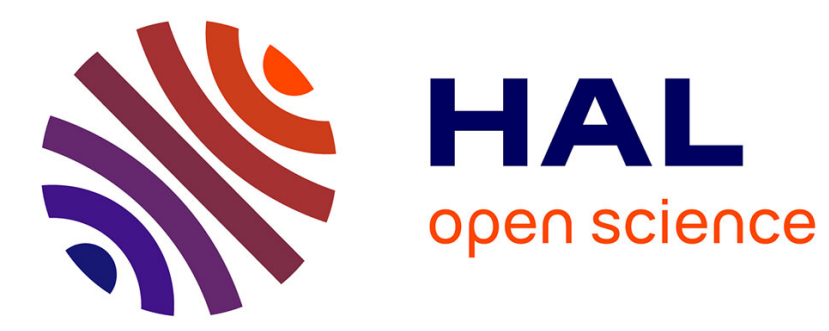

\title{
Using first- and second-order variograms for characterizing landscape spatial structures from remote sensing imagery
}

\author{
Sébastien Garrigues, Denis Allard, Frédéric Baret
}

\section{- To cite this version:}

Sébastien Garrigues, Denis Allard, Frédéric Baret. Using first- and second-order variograms for characterizing landscape spatial structures from remote sensing imagery. IEEE Transactions on Geoscience and Remote Sensing, 2007, 45 (6), pp.1823-1834. 10.1109/TGRS.2007.894572 . hal-02669193

\section{HAL Id: hal-02669193 \\ https://hal.inrae.fr/hal-02669193}

Submitted on 31 May 2020

HAL is a multi-disciplinary open access archive for the deposit and dissemination of scientific research documents, whether they are published or not. The documents may come from teaching and research institutions in France or abroad, or from public or private research centers.
L'archive ouverte pluridisciplinaire HAL, est destinée au dépôt et à la diffusion de documents scientifiques de niveau recherche, publiés ou non, émanant des établissements d'enseignement et de recherche français ou étrangers, des laboratoires publics ou privés. 


\title{
Using First- and Second-Order Variograms for Characterizing Landscape Spatial Structures From Remote Sensing Imagery
}

\author{
Sébastien Garrigues, Denis Allard, and Frédéric Baret
}

\begin{abstract}
The spatial structures displayed by remote sensing imagery are essential information characterizing the nature and the scale of spatial variation of Earth surface processes. This paper provides a new approach to characterize the spatial structures within remote sensing imagery using stochastic models and geostatistic metrics. Up to now, the second-order variogram has been widely used to describe the spatial variations within an image. In this paper, we demonstrate its limitation to discriminate distinct image spatial structures. We introduce a different geostatistic metric, the first-order variogram, which used in combination with the second-order variogram, will prove its efficiency to describe the image spatial structures. We then develop a method based on the simultaneous use of both first- and second-order variogram metrics to model the image spatial structures as the weighted linear combination of two stochastic models: a Poisson line mosaic model and a multi-Gaussian model. The image spatial structures are characterized by the variance weight and the variogram range related to each model. This method is applied to several SPOT-HRV Normalized Difference Vegetation Index (NDVI) images from the VALERI database in order to characterize the nature of the processes structuring different types of landscape. The mosaic model is an indicator of strong NDVI discontinuities within the image mainly generated by anthropogenic processes such as the mosaic pattern of crop sites. The multi-Gaussian model shows evidence of diffuse and continuous variation of NDVI generally engendered by ecological and environmental processes such as the fuzzy pattern observed over forest and natural vegetation sites.
\end{abstract}

Index Terms-First-order variogram, landscape, multiGaussian model, normalized difference vegetation index (NDVI), Poisson line mosaic model, second-order variogram, spatial structure, stochastic simulation.

\section{INTRODUCTION}

T HE MONITORING of Earth surface dynamic processes such as primary production or carbon and water fluxes requires observations of the Earth surface properties at the proper spatial and temporal scales. Remote sensing data are

Manuscript received August 4, 2006; revised November 14, 2006. This paper was mainly completed under a Ph.D. grant allocated to the first author by the French spatial agency Centre National d'Etudes spatiales (CNES) (Toulouse, France) and Alcatel Space Industry (Cannes, France). It benefited also from the availability of the VALERI database under the responsibility of INRA Avignon (France) with funding mainly coming from CNES. Some writing of this paper was sponsored by NASA Grant EOS/03-0408-0637, with thanks to the program manager Dr. Wickland.

S. Garrigues is with the Earth System Science Interdisciplinary Center, University of Maryland, College Park, MD 20742 USA (e-mail: Sebastien. garrigues@gsfc.nasa.gov).

D. Allard is with the Biostatistics and Spatial Processes Unit, INRA, 84914 Avignon, France.

F. Baret is with the UMR1114, INRA, 84914 Avignon, France.

Digital Object Identifier 10.1109/TGRS.2007.894572 particularly appropriate to describe surface processes since they provide continuous and frequent spatial estimates of key Earth surface variables [1]. Contrary to in situ data, remote sensing observations may exhibit the spatial heterogeneity of the retrieved surface property. This information helps characterizing the nature of the processes structuring the landscape [2], identifying their scale of spatial variation [3]-[6] and thus improving their representation in land surface models [7]-[9]. In addition, quantifying the surface spatial heterogeneity from remote sensing data are required to correct the bias associated with nonlinear estimation of land surface variables over heterogeneous pixels [10], [11] and for the disaggregation of coarse spatial resolution images to retrieve the surface property of objects smaller than the pixel size [9], [12], [13]. Appropriate methods must thus be established to extract and efficiently exploit the spatial heterogeneity information contained in remote sensing image.

Garrigues et al. [14] define the spatial heterogeneity of a surface property measured from remote sensing sensor through two components.

1) The spatial variability of the surface property over the observed scene as measured by the variance of the image.

2) The spatial structures: they are defined in this paper as patches or objects (e.g., agricultural fields, vegetation patches,...) that repeat themselves independently within the observed scene at a characteristic length scale (i.e., spatial scale) which represents the extent of the spatial structure. They can be viewed as the typical correlation area (i.e., the typical area of influence) of the surface property. Spatial structures within remotely sensed images are identifiable in that their spectral properties are more homogeneous within them than between them and other scene elements [15]. Data are often distributed into independent sets of spatial structures, related to different length scales and spatial variability, being overlaid in the same region.

This paper focuses specifically on the characterization of the spatial structures observed within remote sensing images. These spatial structures are specific to the measured surface property. The Normalized Difference Vegetation Index (NDVI) computed from red and near infrared reflectances [16] is the "state" variable used in this paper to describe the spatial structures of the landscape vegetation cover.

The characterization of the image spatial structures depends both on the geographic extent of the observed scene and on 


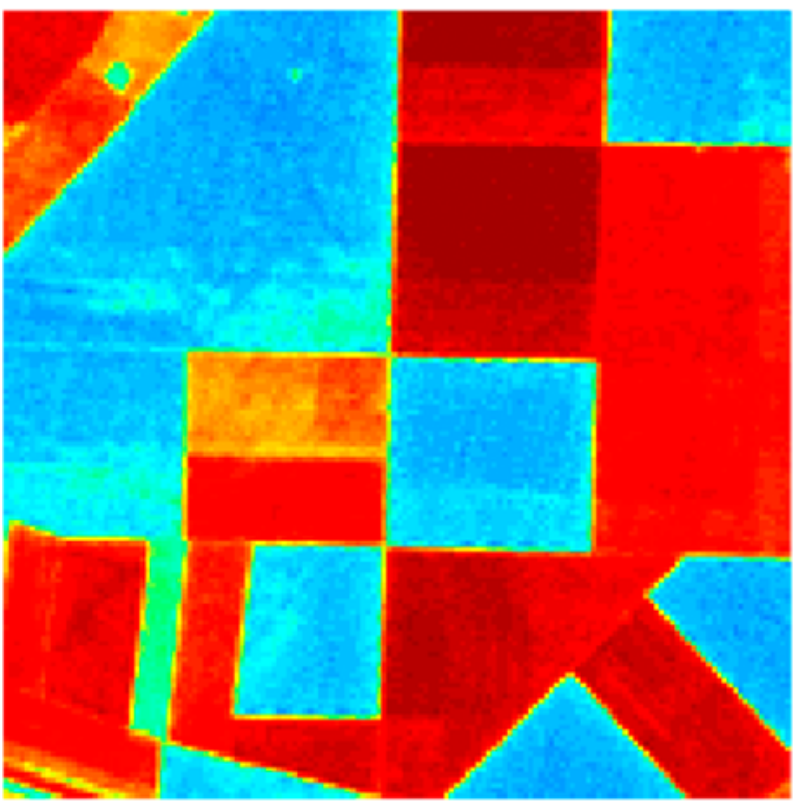

(a)

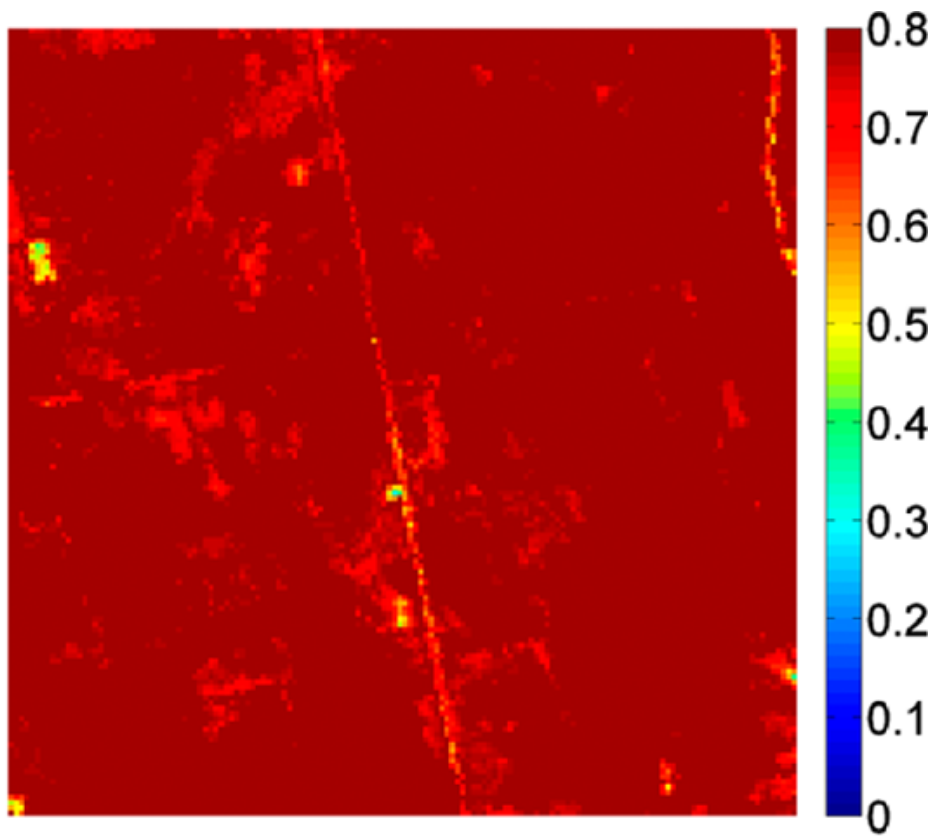

(b)

Fig. 1. Examples of landscape spatial structures characterized from high spatial resolution NDVI images (SPOT-HRV sensor at 20-m spatial resolution). (a) Cropland associated with mosaic spatial structure of the fields. (b) Forest site associated with fuzzy spatial structure of the vegetation cover.

the size of the spatial support on which the signal is integrated [17]-[20]. A scene must be large enough compared to the extent of the spatial structures to encompass their spatial variability [14]. In this paper, the spatial structures of vegetation cover are analyzed at the landscape level defined as an area of few square kilometers (9 to $50 \mathrm{~km}^{2}$ ). Garrigues et al. [14] show that this area is large enough to resolve the spatial variability of most landscape spatial structures. The size of the spatial support of remote sensing data involves two characteristics of the sensor: the ground sampling distance (GSD) and the point spread function (PSF). The GSD is the size of the ground projection of the sensor instantaneous field of view which is approximated by the pixel of the image. Its value at nadir defines the nominal pixel size of the image. In addition, the sensor system applies a low pass spatial filter to the radiometric signal, characterized by the PSF. The width of the PSF affects the size of the actual spatial support of the data which may be larger than the GSD. The combination of PSF and GSD determines the minimum size of the objects detected by the sensor. A surface spatial structure cannot be captured by the data when the size of the spatial support of the data is larger than the extent of the spatial structure [14]. The size of the spatial support of high spatial resolution data (e.g., Satellite Pour 1' Observation de la Terre High Resolution Visible (SPOT-HRV), $\mathrm{GSD}=20 \mathrm{~m}$ ) is small enough to resolve the spatial structures of most landscapes [14]. It is also large enough to limit the noise generated by spatial structures at very small length scales that may hamper the proper characterization of the spatial structures of vegetation cover at the landscape level [14].

In addition, the shape and the variability associated with the spatial structures of vegetation cover depend on the type of landscape [14]. Cropland spatial structures are generally characterized by a mosaic pattern and generate large NDVI spatial variability [Fig. 1(a)]. Spatial structures of natural vegetation and forest have fuzzier pattern and are associated with smaller NDVI variability than agricultural field structures [Fig. 1(b)].

Several metrics can be used to describe the spatial variations within an image. Julesz [21] underlines that one point statistics (e.g., image histogram) are not efficient to describe image spatial variations since they do not account for spatial correlations between data. Two point statistics which describe the spatial relationships between data are thus more appropriate [21]-[23]. Garrigues et al. [14] provide a comparison of some two point statistics metrics used to explore the spatial variations within an image which includes Haralick indexes [23], fractal and multifractal analysis [24]-[28], Fourier transform [29], [30], wavelet transform [6], [25], [30], and second-order variogram [15], [31]-[37]. Among these metrics, it is shown in Garrigues et al. [14] that modeling the second-order variogram of high spatial resolution NDVI image is an efficient method to characterize the spatial structures of the landscape. In their approach, variogram parameters are related to the length scales and the spatial variability associated with each set of spatial structures being overlaid in the image.

However, Gagalowicz [22] shows that the information provided by the second-order variogram is not always sufficient to discriminate different types of spatial structure. This fact is also illustrated in Chilès and Delfiner [32] in which it is shown that several models of random functions can have exactly the same theoretical second-order variogram. In this paper, we propose to use another geostatistic tool, the first-order variogram which, together with second-order variogram, will prove to be powerful to describe the image spatial structure. Up to now, the first-order variogram has never been applied to remote sensing imagery. In addition, no studies have been specifically focusing on modeling the characteristics of the image spatial structures such as their size and shape in order to characterize the underlying processes structuring the landscape. 
TABLE I

Data Base (Detailed Information on Each Site Are Available ON THE VALERI WEB SITE www.avignon.inra.fr/valeri). DATE IS THE ACQUISITION MONTH OF THE IMAGE. $m_{\text {NDVI }}$ AND $\sigma_{\text {NDVI }}$ ARE THE MEAN AND STANDARD DEVIATION OF THE NDVI IMAGE

\begin{tabular}{|l|l|r|r|r|r|c|}
\hline Site name & Biome (FAO classification) & Date & Latitude & Longitude & $m_{\text {NDI }}$ & $\sigma_{\text {NDVI }}$ \\
\hline Fundulea01 & Cropland & May & 44.41 & 26.58 & 0.51 & 0.23 \\
\hline SudOuest02 & Cropland & July & 43.51 & 1.24 & 0.50 & 0.17 \\
\hline Alpilles02 & Cropland & July & 43.81 & 4.74 & 0.38 & 0.16 \\
\hline Jarvselja01 & Mixed forest & July & 58.29 & 27.29 & 0.82 & 0.05 \\
\hline Nezer01 & Needleleaf forest (pine forest) & June & 44.51 & -1.04 & 0.66 & 0.06 \\
\hline Puechabon01 & $\begin{array}{l}\text { Closed shrubland (Mediterranean. } \\
\text { vegetation) }\end{array}$ & June & 43.72 & 3.65 & 0.54 & 0.10 \\
\hline
\end{tabular}

The objective of this paper is to develop an approach based on stochastic models and the simultaneous use of both firstand second-order variograms in order to characterize the spatial structures of various types of landscape from high spatial resolution NDVI images. The rest of this paper is organized as follows. Section II describes the six SPOT-HRV scenes extracted from the Validation of Land European Remote sensing Instruments (VALERI) database and used in this paper to describe the spatial structures of the landscape vegetation cover. In Section III, the stochastic models used to model the spatial structures within remote sensing images are presented. The limitation of the second-order variogram and the potentials of the simultaneous use of both first- and second-order variograms to describe distinct image spatial structures are illustrated on simulated images in Section IV. Section V is dedicated to the method used to estimate the parameters of the stochastic models characterizing the image spatial structures. In Section VI, the implemented method is first validated on simulated images and then applied to the actual SPOT-HRV NDVI images of the landscapes under study. Finally, the accuracy of the implemented method is discussed in Section VII.

\section{DATA DESCRIPTION}

The data used here are part of the VALERI database (www.avignon.inra.fr/valeri; [38]) which provides SPOT-HRV scenes at 20-m spatial resolution for several landscapes sampled through the world. For this paper, six contrasted spatial heterogeneity sites were selected (Table I). Each site has the following characteristics: $3 \times 3 \mathrm{~km}$ size; flat topography; it contains one or two types of vegetation. The vegetation cover is described over each SPOT-HRV scene by the NDVI, denoted $z(x)$ (where $x$ represents an image pixel), computed from red $(r(x))$ and near infrared $(p(x))$ SPOT-HRV spectral bands

$$
z(x)=\frac{p(x)-r(x)}{p(x)+r(x)} .
$$

The SPOT-HRV scenes are georeferenced in the UTM/ WGS84 projection. They are not contaminated by clouds. They are not corrected for atmospheric scattering and absorption. But, for most scenes, the atmospheric effects are low in the red and near-infrared bands and their spatial variability is small over $3 \times 3 \mathrm{~km}$ scenes [38].

The characterization of landscape spatial structures from the selected NDVI images requires several hypotheses. $H_{1}$ : the image extent $(3000 \mathrm{~m})$ is large with respect to the spatial features of interest, and any spatial structures extending beyond the image extent is considered as apparent trends. $H_{2}$ : the radiometric measurement errors (cloud detection, atmospheric effects, view geometry and illumination effects, shadow effects, resampling effects,...) are small relative to the surface variations. Because the combination of the PSF and the GSD of the sensor are such that effects of spatial variations within a pixel are very small relative to the environmental variations, we state the following third hypothesis. $H_{3}$ : spatial variations at a scale smaller than the GSD can be neglected. In addition, we consider high spatial resolution radiometric data as punctual $\left(H_{4}\right)$.

\section{Stochastic Modeling}

Remote sensing images will be considered as realizations of second-order stationary stochastic processes $Z(x)$ also called random functions [32]. Second-order stationarity of the random function $Z(x)$ supposes the existence and the stationarity of the first two moments [32], [39]

$$
E[Z(x)]=m \quad \operatorname{Cov}(Z(x), Z(x+h))=C(h)
$$

for all image pixels $x$ and vector $h$ between two image pixels. The function $C(h)$ is the covariance function of $Z(x)$. It characterizes the spatial distribution of $Z(x)$. In the following, we will consider isotropic stochastic processes, for which the covariance function is a function of the Euclidian distance $\|h\|$ only. Under second-order stationarity assumption, the secondorder variogram $\gamma_{2}(h)$ of $Z(x)$ which describes the variability between two pixel values of the image separated by a distance $\|h\|$

$$
\gamma_{2}(h)=0.5 \operatorname{Var}[Z(x+h)-Z(x)]
$$

is related to the covariance function according to the relationship

$$
\gamma_{2}(h)=\sigma^{2}-C(h)
$$

where $\sigma^{2}$ is the variance of $Z(x)$. Note that the second-order variogram is the "usual" variogram used in the geostatistic literature. It is a function starting from 0 for $\|h\|=0$ and ultimately converging to the sill $\sigma^{2}$ as $\|h\|$ tends to infinity. The range of the second-order variogram is the distance at which it reaches a sill. Data separated by a distance larger than the range are uncorrelated. The range is related to the length scale (i.e., spatial scale) of the data.

Since the existence of finite second-order moments (i.e., covariance function and second-order variogram) implies the existence of finite first-order moments, one can also define the first-order variogram of $Z(x), \gamma_{1}(h)$ [32]

$$
\gamma_{1}(h)=\frac{1}{2} E[|Z(x+h)-Z(x)|] .
$$

It will be shown in Section III-B2 that the first-order variogram provides some additional information to the second-order variogram, that will prove to be useful for characterizing image spatial structures. 


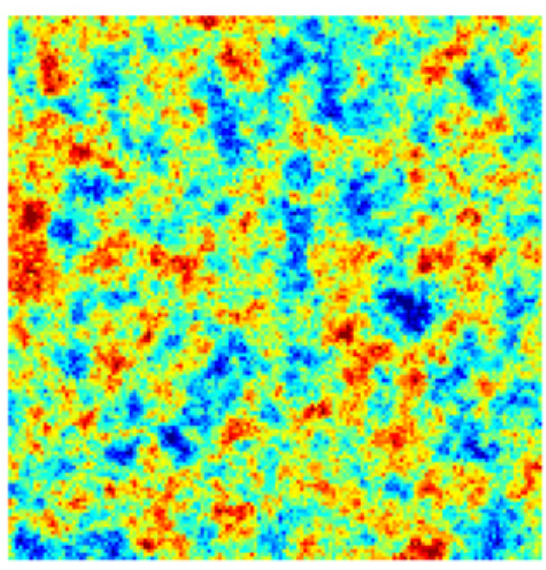

(a)

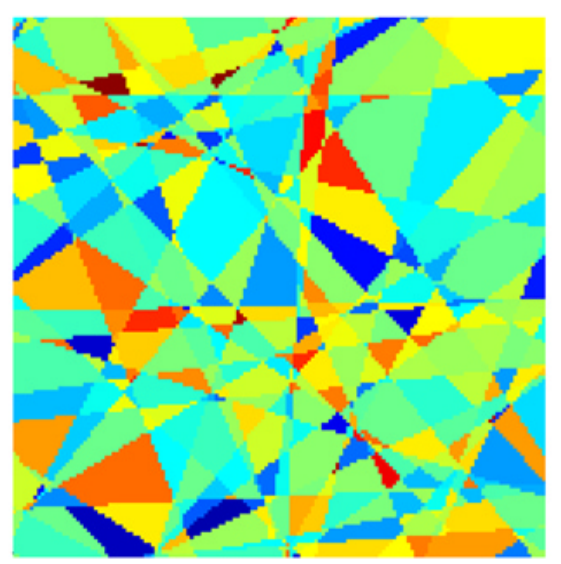

(b)

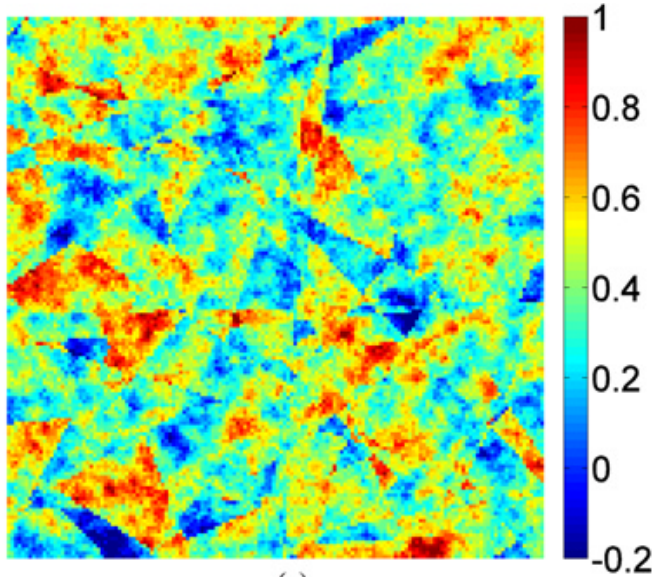

(c)

Fig. 2. Images simulated according to the three following random functions: (a) $Z_{8}(x)$ is the pure multi-Gaussian model $\left(\omega_{8}^{2}=1\right)$; (b) $Z_{0}(x)$ is the pure mosaic model $\left(\omega_{0}^{2}=0\right)$; (c) $Z_{4}(x)$ is the linear combination of the mosaic and multi-Gaussian model with $50 \%$ of variance weight associated with each model $\left(\omega_{4}^{2}=0.5\right)$.

In this paper, we consider that the image spatial structures are a combination of two stochastic second-order stationary models. The first model corresponds to diffuse images and continuous variations; it is the multi-Gaussian model denoted $Z_{\mathrm{g}}(x)$. The second model is a tessellation model: The domain is randomly separated into nonoverlapping cells; in each cell a constant, yet random, value is independently drawn. It is called the mosaic model and is denoted $Z_{\mathrm{m}}(x)$. The linear combination of these two stochastic models defines the mixture model. A set of images simulated from the mixture model will be used to establish a method to characterize the image spatial structures.

The following section presents in more details the two stochastic models used in this paper. The second section describes the mixture model along with the theoretical expressions of its first- and second-order variograms.

\section{A. Two Stationary Stochastic Models}

1) Multi-Gaussian Model $\left(Z_{\mathrm{g}}(x)\right)$ : A random function $Z_{\mathrm{g}}(x)$ is a multi-Gaussian random function if any finite vector $\boldsymbol{Z}=\left(Z\left(x_{1}\right), \ldots, Z\left(x_{n}\right)\right)$ is distributed according to a multivariate Gaussian distribution [32]. A stationary multivariate Gaussian random function is fully characterized by its mathematical expectation $m$ and its covariance function $C(h)$. Many different algorithms are available to generate nonconditional simulations of the multi-Gaussian model [40]. We have used the turning band method [32]. In the following, we will consider standard multi-Gaussian models for which $m=0$ and $\sigma^{2}=$ $C(0)=1$. If the parametric family of the covariance function is specified, the only input parameter for this stochastic process is its range $r_{\mathrm{g}}$. In this paper, an exponential family of covariance function is chosen for the multi-Gaussian model. The secondorder variogram of $Z_{\mathrm{g}}(x)$, denoted $\gamma_{2, \mathrm{~g}}\left(h ; r_{\mathrm{g}}\right)$, is thus an exponential variogram defined by

$$
\gamma_{2, \mathrm{~g}}\left(h ; r_{\mathrm{g}}\right)=1-\exp \left\{-\frac{3\|h\|}{r_{\mathrm{g}}}\right\}
$$

where $r_{\mathrm{g}}$ is the practical range of the variogram, i.e., the distance at which the variogram reaches $95 \%$ of the variogram sill [32]. A realization of a multi-Gaussian random function with exponential second-order variogram is represented in Fig. 2(a).

For a stationary Gaussian random function $Z_{\mathrm{g}}(x)$, the difference $Z_{\mathrm{g}}(x+h)-Z_{\mathrm{g}}(x)$ is a Gaussian random variable with mean equal to zero and variance equal to $2 \gamma_{\mathrm{g}}\left(h ; r_{\mathrm{g}}\right)$. Using the formula for the expectation of the absolute value of a Gaussian random variable $G(x)$ with zero mean and variance $\tau^{2}$

$$
E|G(x)|=\frac{\sqrt{2 \tau^{2}}}{\sqrt{\pi}}
$$

the first-order variogram $\gamma_{1, \mathrm{~g}}\left(h ; r_{\mathrm{g}}\right)(5)$ of the multi-Gaussian model is easily shown to be equal to

$$
\gamma_{1, \mathrm{~g}}\left(h ; r_{\mathrm{g}}\right)=\frac{1}{\sqrt{\pi}} \sqrt{\gamma_{2, \mathrm{~g}}\left(h ; r_{\mathrm{g}}\right)} .
$$

2) Mosaic Model-The Poisson Lines Model $\left(Z_{\mathrm{m}}(x)\right)$ : A mosaic model is a tessellation model that randomly partitions the image into nonoverlapping cells [32]. To each cell of the tessellation is independently assigned a value drawn from the same probability density distribution (pdf). Because each pixel $x$ belongs to only one cell, this model defines a random function $Z_{\mathrm{m}}(x)$, that can be described by its covariance function. The Poisson tessellation model [41] is a tessellation generated by Poisson random lines. A line is fully specified by two parameters: a direction, denoted $\alpha$ with $\alpha$ in $[0,2 \pi)$, and a distance to the origin, denoted $d$ with $d>0$. Poisson random lines are distributed according to the following random process. The number of lines intersecting the image, denoted $N(I)$, is first drawn from a Poisson distribution with parameter $Y_{I}$. Then, each line is drawn with independent uniform distributions for $\alpha$ and $d$, subject to the condition that the line intersects the image. The only parameter driving the Poisson random lines model is the parameter $Y_{I}$ : to large values of $Y_{I}$ correspond small cells and vice versa. Regarding the random values in the cells, we will consider in this paper the case of independent standard $\left(m=0, \sigma^{2}=1\right)$ Gaussian random variables. The 
combination of Poisson random lines and independent standard $(0,1)$ Gaussian random variables within each cell defines our mosaic random function $Z_{\mathrm{m}}(x)$. A typical realization of a Poisson tessellation random function is depicted in Fig. 2(b). Lantuéjoul [41] shows that the covariance function $C_{\mathrm{m}}(h)$ of the mosaic model has an exponential form

$$
\operatorname{Cov}\left(Z_{\mathrm{m}}(x), Z_{\mathrm{m}}(x+h)\right)=C_{\mathrm{m}}(h)=\exp \left\{-\frac{3\|h\|}{r_{\mathrm{m}}}\right\}
$$

with

$$
r_{\mathrm{m}}=\frac{3}{2} \frac{L_{I}}{N(I)}
$$

where $L_{I}$ is the image perimeter and $r_{\mathrm{m}}$ is the practical range of $C_{\mathrm{m}}(h)$. The second-order variogram of the mosaic model, denoted $\gamma_{2, \mathrm{~m}}\left(h ; r_{\mathrm{m}}\right)$, is thus an exponential variogram

$$
\gamma_{2, \mathrm{~m}}\left(h ; r_{\mathrm{m}}\right)=1-\exp \left\{-\frac{3\|h\|}{r_{\mathrm{m}}}\right\} .
$$

It will be shown in Section III-B2, that the first-order variogram of the mosaic model is defined by

$$
\gamma_{1, \mathrm{~m}}\left(h ; r_{\mathrm{m}}\right)=\frac{1}{\sqrt{\pi}} \gamma_{2, \mathrm{~m}}\left(h ; r_{\mathrm{m}}\right) .
$$

It is important to stress that, by construction, both random functions $Z_{\mathrm{g}}(x)$ and $Z_{\mathrm{m}}(x)$ have the same marginal standard $(0,1)$ Gaussian distribution. Moreover, because we have chosen an exponential covariance for the multi-Gaussian model, they are both characterized by the same exponential family of second-order variogram model. But they have different first-order variogram. More importantly, the mosaic model is characterized by a linear relationship between the first- and second-order variograms (12), while the multi-Gaussian model is characterized by a quadratic relationship (8). This difference will be the basis of the method presented in Section V for distinguishing between the two stochastic processes.

\section{B. Mixture Model}

The two models defined above are now combined to define the mixture model as follows:

$$
Z(x)=\sigma\left(\omega Z_{\mathrm{g}}(x)+\sqrt{\left(1-\omega^{2}\right)} Z_{\mathrm{m}}(x)\right)+m
$$

where $m$ is the mathematical expectation of $Z(x), \sigma^{2}$ is its variance, $\omega^{2}$ and $\left(1-\omega^{2}\right)$ are the fractions of the total variance of $Z(x)$ explained by the multi-Gaussian model $Z_{\mathrm{g}}(x)$ and the mosaic model $Z_{\mathrm{m}}(x)$, respectively. Note that according to (13), the random function $Z(x)$ has the same marginal $\left(m, \sigma^{2}\right)$ Gaussian pdf for all values $\omega$.

The following sections establish the theoretical expression of the first- and second-order variograms of the mixture model.

1) Second-Order Variogram: Since $Z(x)$ is a weighted sum of the independent random functions $Z_{\mathrm{g}}(x)$ and $Z_{\mathrm{m}}(x)$ (13), its second-order variogram $\gamma_{2}(h)$ (3) is the weighted sum of the second-order variograms of $Z_{\mathrm{g}}(x)$ and $Z_{\mathrm{m}}(x)$ [32]

$$
\gamma_{2}(h)=\sigma^{2}\left(\omega^{2} \gamma_{2, \mathrm{~g}}\left(h ; r_{\mathrm{g}}\right)+\left(1-\omega^{2}\right) \gamma_{2, \mathrm{~m}}\left(h ; r_{\mathrm{m}}\right)\right) .
$$

Note that if $r_{\mathrm{g}}=r_{\mathrm{m}}$, (14) simplifies as follows:

$$
\gamma_{2}(h)=\sigma^{2} \gamma_{2, \mathrm{~g}}\left(h ; r_{\mathrm{g}}\right)=\sigma^{2} \gamma_{2, \mathrm{~m}}\left(h ; r_{\mathrm{m}}\right)
$$

for all value $\omega^{2}$. Equation (15) shows that the second-order variogram is the same exponential variogram for all value $\omega^{2}$. In other words, in the case of $r_{\mathrm{g}}=r_{\mathrm{m}}$ the second-order variogram $\gamma_{2}(h)$ cannot distinguish between a multi-Gaussian structure and a mosaic structure.

2) First-Order Variogram: Establishing the first-order variogram of the mixture model defined in (13) requires developing (5) by conditioning on the underlying Poisson line process used to generate the mosaic model $Z_{\mathrm{m}}(x)$. As described in Section III-A2, the tessellation process of Poisson lines partitions the plan into nonoverlapping cells within the image. The cell values are realization of independent standard $(0,1)$ Gaussian random variables. The probability that two image pixels $x$ and $x+h$ separated by a distance $\|h\|$ belong to the same cell, denoted event $A$, is related to the covariance function of $Z_{\mathrm{m}}(x)$ [41] and thus to the second-order variogram of $Z_{\mathrm{m}}(x)$

$$
P(A)=C_{\mathrm{m}}(h)=1-\gamma_{2, \mathrm{~m}}\left(h, r_{\mathrm{m}}\right) .
$$

Thus, the probability that they do not belong to the same cell (event $\bar{A}$ ) is equal to

$$
P(\bar{A})=1-P(A)=\gamma_{2, \mathrm{~m}}\left(h ; r_{\mathrm{m}}\right) .
$$

Conditioning on the event $A$ and $\bar{A}$, the theoretical first-order variogram (5) can be decomposed as follows:

$$
\begin{aligned}
\gamma_{1}(h)=0.5 P(A) E & {[|Z(x+h)-Z(x)| / A] } \\
+ & 0.5 P(\bar{A}) E[|Z(x+h)-Z(x)| / \bar{A}] .
\end{aligned}
$$
to $(13)$

a) Calculation of $E[|Z(x+h)-Z(x)| / A]$ : According

$$
\begin{gathered}
E[|Z(x+h)-Z(x)| / A]=E\left[\mid \sigma\left(\omega\left(Z_{\mathrm{g}}(x+h)-Z_{\mathrm{g}}(x)\right)\right.\right. \\
\left.\left.+\sqrt{\left(1-\omega^{2}\right)}\left(Z_{\mathrm{m}}(x+h)-Z_{\mathrm{m}}(x)\right)\right) \mid / A\right] .
\end{gathered}
$$

In the case of event $A$, the locations $x$ and $x+h$ are in the same cell. As a result, $Z_{\mathrm{m}}(x)-Z_{\mathrm{m}}(x+h)=0$. Since $Z_{\mathrm{g}}(x+h)$ and $Z_{\mathrm{g}}(x)$ are second-order stationary and spatially dependent standard Gaussian random functions, their difference is a Gaussian random function with mean equal to zero and variance equal to $2 \gamma_{2, \mathrm{~g}}\left(h ; r_{\mathrm{g}}\right)$. Using the formula for the expectation of the absolute value of a Gaussian random variable (7), (19) simplifies as follows:

$$
\begin{aligned}
E[|Z(x+h)-Z(x)| / A] & =\sigma \omega E\left[\left|Z_{\mathrm{g}}(x+h)-Z_{\mathrm{g}}(x)\right|\right] \\
& =2 \sigma \omega \frac{\sqrt{\gamma_{2, \mathrm{~g}\left(h ; r_{\mathrm{g}}\right)}}}{\sqrt{\pi}}
\end{aligned}
$$



to $(13)$

b) Calculation of $E[|Z(x+h)-Z(x)| / \bar{A}]$ : According

$$
\begin{gathered}
E[|Z(x+h)-Z(x)| / \bar{A}]=E\left[\mid \sigma\left(\omega\left(Z_{\mathrm{g}}(x+h)-Z_{\mathrm{g}}(x)\right)\right.\right. \\
\left.\left.+\sqrt{\left(1-\omega^{2}\right)}\left(Z_{\mathrm{m}}(x+h)-Z_{\mathrm{m}}(x)\right)\right) \mid / \bar{A}\right] .
\end{gathered}
$$

In the case of the event $\bar{A}$, the pixels $x$ and $x+h$ do not belong to the same cell. Thus, $Z_{\mathrm{m}}(x+h)$ and $Z_{\mathrm{m}}(x)$ are two independent Gaussian random functions. $\sqrt{\left(1-\omega^{2}\right)}\left(Z_{\mathrm{m}}(x+\right.$ $\left.h)-Z_{\mathrm{m}}(x)\right)$ is thus a Gaussian random function with mean equal to zero and variance equal to $2\left(1-\omega^{2}\right)$. As in the case of event $A, \omega\left(Z_{\mathrm{g}}(x+h)-Z_{\mathrm{g}}(x)\right)$ is a Gaussian random function with mean equal to zero and variance equal to $2 \omega^{2} \gamma_{2, \mathrm{~g}}\left(h ; r_{\mathrm{g}}\right)$. Therefore, $\sqrt{\left(1-\omega^{2}\right)}\left(Z_{\mathrm{m}}(x+h)-Z_{\mathrm{m}}(x)\right)$ and $\omega\left(Z_{\mathrm{g}}(x+\right.$ $\left.h)-Z_{\mathrm{g}}(x)\right)$ are two independent Gaussian random functions. Their sum is thus a Gaussian random function with mean equal to zero and variance equal to $2\left(1-\omega^{2}\right)+2 \omega^{2} \gamma_{2, \mathrm{~g}}\left(h ; r_{\mathrm{g}}\right)$. Using the formula for the expectation of the absolute value of a Gaussian random variable (7), (21) thus becomes

$E[|Z(x+h)-Z(x)| / \bar{A}]=2 \sigma \frac{\sqrt{\omega^{2} \gamma_{2, \mathrm{~g}}\left(h ; r_{\mathrm{g}}\right)+\left(1-\omega^{2}\right)}}{\sqrt{\pi}}$.

Given (20) and (22), the theoretical first-order variogram of $Z(x)(18)$ is

$$
\begin{aligned}
\gamma_{1}(h)= & \frac{1}{\sqrt{\pi}} \sigma\left[\omega\left(1-\gamma_{2, \mathrm{~m}}\left(h ; r_{\mathrm{m}}\right)\right) \sqrt{\gamma_{2, \mathrm{~g}}\left(h ; r_{\mathrm{g}}\right)}\right. \\
& \left.+\gamma_{2, \mathrm{~m}}\left(h ; r_{\mathrm{m}}\right) \sqrt{\omega^{2} \gamma_{2, \mathrm{~g}}\left(h ; r_{\mathrm{g}}\right)+\left(1-\omega^{2}\right)}\right] .
\end{aligned}
$$

As stated in Section III-A, (23) demonstrates that the relationship between the first- and second-order variograms is linear for the mosaic model [by replacing $\omega=0$ and $\sigma=1$ in (23) we obtain (12)] and quadratic for the multi-Gaussian model [by replacing $\omega=1$ and $\sigma=1$ in (23) we obtain (8)].

Equation (23) shows that even for $r_{\mathrm{g}}=r_{\mathrm{m}}$, the first-order variogram depends on $\omega^{2}$. The first-order variogram can thus be used to distinguish between a multi-Gaussian structure and a mosaic structure. We will use this property in Section V.

The following section provides some illustration of these theoretical results on simulated images.

\section{EXPERIMENTAl Results on Simulated IMAgeS}

The simulation method consists in first generating an image from the multi-Gaussian model with the parameter $r_{\mathrm{g}}$ and another image from the mosaic model with the parameter $r_{\mathrm{m}}$. These images are then combined according to (13) to produce an image from the mixture model $Z(x)$. Since the parameters $m$ and $\sigma^{2}$ do not affect the characterization of the image spatial structures, they will be set for all the simulations at $m=0.4$ and $\sigma^{2}=0.04$. For a given set of parameters $r_{\mathrm{g}}$ and $r_{\mathrm{m}}$, and for fixed images $Z_{\mathrm{g}}(x)$ and $Z_{\mathrm{m}}(x)$, several random images $Z_{i}(x)$ are generated by varying the parameter $\omega_{i}^{2}$ (Table II), from $\omega_{0}^{2}=0$ to $\omega_{8}^{2}=1$. Each corresponding random function $Z_{i}(x)$,
TABLE II

DEFINITION OF THE RANDOM FUnCTIONS $Z_{i}(x)$ AS A FunCtion of $\omega_{i}^{2}$

\begin{tabular}{|l|l|l|l|l|l|l|l|l|l|}
\hline$Z_{i}$ & $Z_{0}$ & $Z_{1}$ & $Z_{2}$ & $Z_{3}$ & $Z_{4}$ & $Z_{5}$ & $Z_{6}$ & $Z_{7}$ & $Z_{8}$ \\
\hline$\omega_{i}{ }^{2}$ & 0 & 0.125 & 0.25 & 0.36 & 0.5 & 0.64 & 0.75 & 0.875 & 1 \\
\hline
\end{tabular}

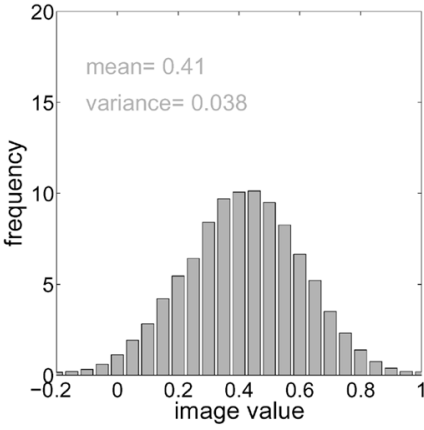

(a)

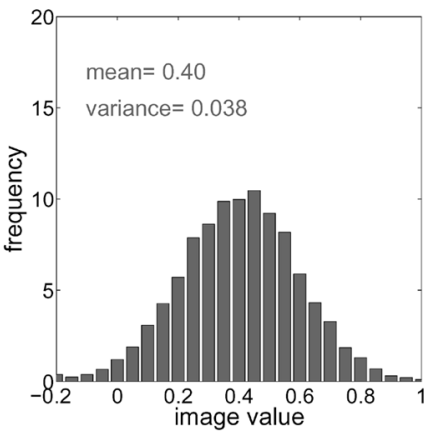

(c)

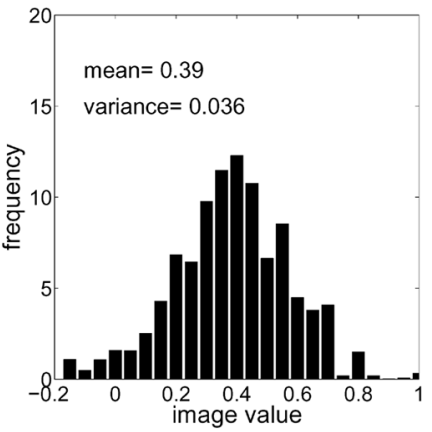

(b)
Fig. 3. Histograms of the images displayed in Fig. 2 simulated according to the three following random functions: (a) $Z_{8}(x)$ is the pure multi-Gaussian model $\left(\omega_{8}^{2}=1\right)$; (b) $Z_{0}(x)$ is the pure mosaic model $\left(\omega_{0}^{2}=0\right)$; (c) $Z_{4}(x)$ is the linear combination of the mosaic and multi-Gaussian model with $50 \%$ of variance weight associated with each model $\left(\omega_{4}^{2}=0.5\right)$.

$i=0, \ldots, 8$, i.e., each corresponding image spatial structure, will thus be defined by the three parameters $r_{\mathrm{g}}, r_{\mathrm{m}}$, and $\omega_{i}^{2}$.

The simulations are performed over a raster grid of $150 \times$ 150 pixels with a pixel size of $20 \mathrm{~m}$. To limit the influence of the variability within the stochastic process, 20 images are generated for a given random function $Z_{i}(x)$. All experimental metrics used to describe the image along this paper are averaged over the 20 images.

In this section, we consider mixture models characterized by the same Gaussian pdf ( $m=0.4$ and $\left.\sigma^{2}=0.04\right)$, as well as the same theoretical exponential second-order variogram with $r_{\mathrm{g}}=r_{\mathrm{m}}=300 \mathrm{~m}$.

Fig. 2 exhibits three images simulated from different mixture models $Z_{i}(x)$ : a pure mosaic model $\left(Z_{0}(x), \omega_{0}^{2}=0\right)$, a pure multi-Gaussian model $\left(Z_{8}(x), \omega_{8}^{2}=1\right)$ and a balanced mixture of both models $\left(Z_{4}(x), \omega_{4}^{2}=0.5\right)$. The spatial structures displayed by these images are visually distinct.

As stated above these images have the same theoretical Gaussian histograms. Fig. 3 provides the histogram computed on the images displayed on Fig. 2. As expected, the general shape is identical for all histograms, with increasing statistical fluctuations as the proportion of the mosaic model increases (see comment on this point below). This illustrates results from Julesz [21] who demonstrated that one point statistics (e.g., image histogram) are not sufficient to characterize the 


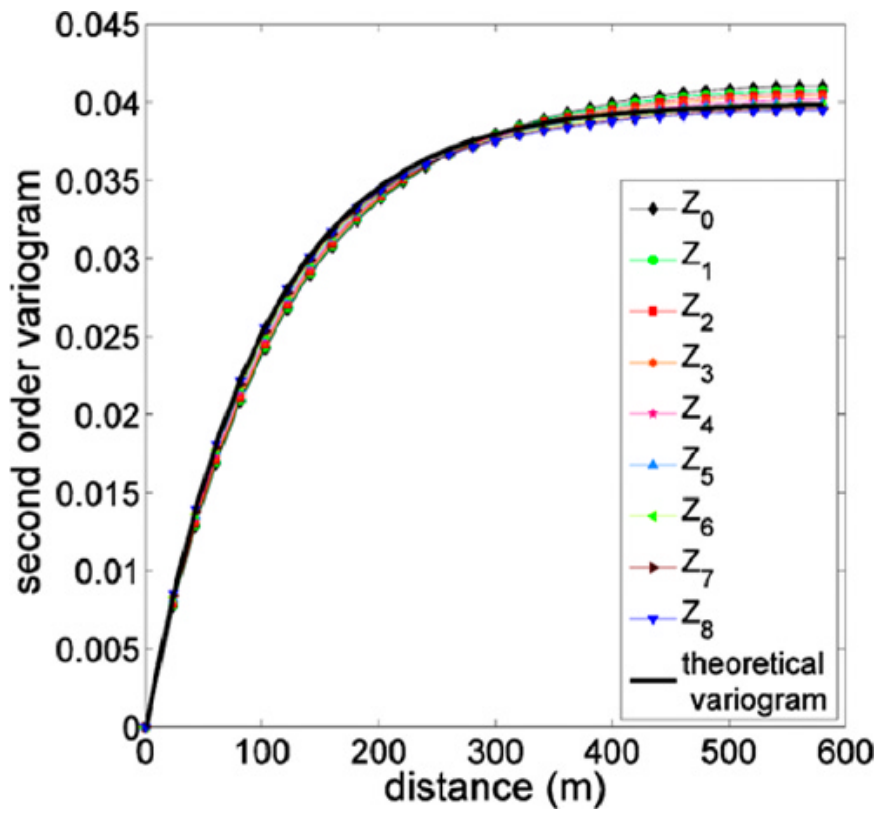

Fig. 4. Experimental second-order variograms computed over images simulated from the random functions $Z_{i}(x),(i=0, \ldots, 8)$. The thick black line represents the theoretical second-order variogram (exponential model with $r_{\mathrm{g}}=r_{\mathrm{m}}=300 \mathrm{~m}$ ) used for the simulations.

image spatial structures since they do not describe the spatial correlations between data.

The experimental second-order variogram

$$
\gamma_{2, e}(h)=\frac{1}{2 N(h)} \sum_{\left\|x_{\alpha}-x_{\beta}\right\| \approx\|h\|}\left(z\left(x_{\alpha}\right)-z\left(x_{\beta}\right)\right)^{2}
$$

measures the average of squared differences between values $z\left(x_{\alpha}\right)$ and $z\left(x_{\beta}\right)$ of all pairs of pixels $\left(x_{\alpha}, x_{\beta}\right)$ separated by a distance $\left\|x_{\alpha}-x_{\beta}\right\|=\|h\| . N(h)$ is the number of the pairs of pixels separated by the distance $\|h\|$. The experimental secondorder variogram is the estimator of the theoretical second-order variogram presented in (3). Fig. 4 displays the experimental second-order variogram computed over images simulated from the random functions $Z_{i}(x),(i=0, \ldots, 8)$ along with the theoretical exponential second-order variogram of $Z(x)$. The experimental second-order variograms are similar and close to the theoretical variogram. Similarly to histograms, variograms display increasing statistical fluctuations as the proportion of the mosaic model increases in the mixture model (decreasing $\omega)$. The reason is that the simulations of the mosaic model are more variable than those of the multi-Gaussian model. This could be shown using theoretical properties of the mosaic model, but for the sake of brevity, we will not elaborate on this specific topic.

Fig. 4 thus illustrates the theoretical result of Section III-B1 demonstrating that for $r_{\mathrm{g}}=r_{\mathrm{m}}$ the second-order variogram $\gamma_{2}(h)$ cannot distinguish between a multi-Gaussian structure and a mosaic structure. It also illustrates the more general fact pointed out by Gagalowicz [22], that the information provided by the second-order variogram may not be sufficient to discriminate the image spatial structures.

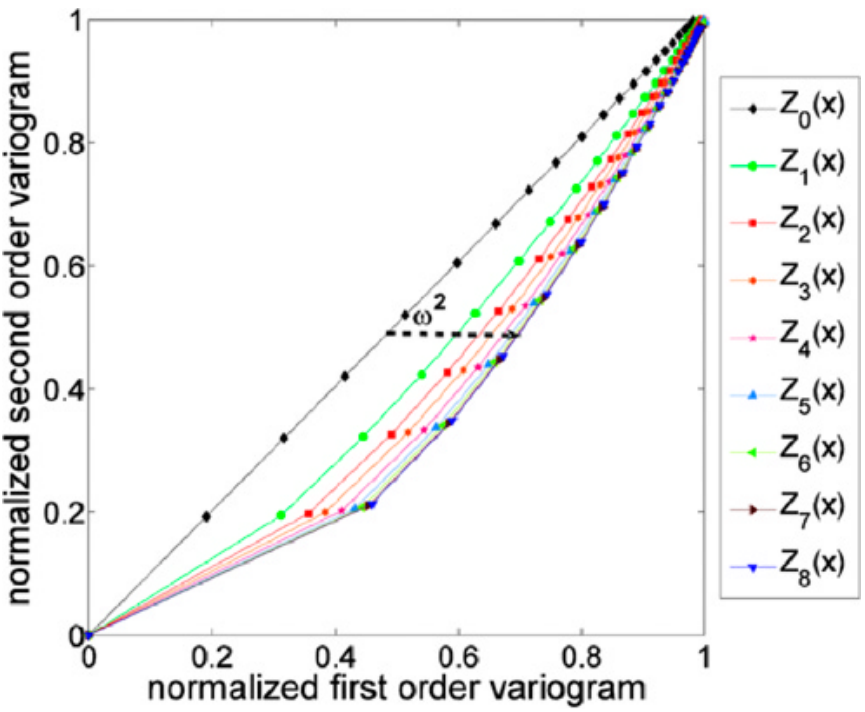

Fig. 5. Normalized experimental first- and second-order variogram computed over images simulated from the random functions $Z_{i}(x),(i=0, \ldots, 8)$. The arrow indicates increasing value of the variance weight $\omega^{2}$ associated with the multi-Gaussian model used to simulate the images.

Similarly to (24), the experimental first-order variogram is computed according to

$$
\gamma_{1, e}(h)=\frac{1}{2 N(h)} \sum_{\left\|x_{\alpha}-x_{\beta}\right\| \approx h}\left|z\left(x_{\alpha}\right)-z\left(x_{\beta}\right)\right| .
$$

The experimental first-order variogram is the estimator of the theoretical first-order variogram presented in (5). Fig. 5 exhibits for each image simulated according to the random functions $Z_{i}(x),(i=0, \ldots, 8)$ the normalized experimental second-order variogram (27) as a function of the normalized experimental first-order variogram (26)

$$
\begin{aligned}
\gamma_{1, e, n}(h) & =\frac{\gamma_{1, e}}{\sigma} \sqrt{\pi} \\
\gamma_{2, e, n}(h) & =\frac{\gamma_{2, e}}{\sigma^{2}} .
\end{aligned}
$$

Each random function $Z_{i}(x)$ has a different $\left(\gamma_{1, e, n}(h)\right.$; $\left.\gamma_{2, e, n}(h)\right)$ signature which varies with the variance weight $\omega^{2}$ of the multi-Gaussian model with respect to that of the mosaic model. Fig. 5 illustrates the theoretical result of Section III-B2 showing that the relationship between first- and second-order variograms is linear for the mosaic model $\left(\omega^{2}=0\right)$ and quadratic for the multi-Gaussian model $\left(\omega^{2}=1\right)$.

This result suggests using simultaneously both first- and second-order variograms to describe the image spatial structures as the result of the combination of a multi-Gaussian and mosaic model. The following section presents a method based on this result to characterize the spatial structures within the images.

\section{Estimation of the Mixture Model Parameters}

The approach consists in describing the spatial structures of the NDVI images under study using the mixture model $Z(x)$ (13), i.e., as the result of the combination of a mosaic 
and a multi-Gaussian model. The experimental variogram metrics $\gamma_{1, e}(h)$ and $\gamma_{2, e}(h)$ computed over the image are used as estimators of the theoretical variograms $\gamma_{1}(h)$ and $\gamma_{2}(h)$, respectively, to retrieve the parameters $\omega^{2}, r_{\mathrm{g}}$, and $r_{\mathrm{m}}$ characterizing $Z(x)$. A lookup table (LUT) is used to estimate the parameters $\omega^{2}, r_{\mathrm{g}}$, and $r_{\mathrm{m}}$. It relates the values of the theoretical first- and second-order variograms computed for $N_{d}$ class of distances to different combinations of the parameters $\omega^{2}, r_{\mathrm{g}}$, and $r_{\mathrm{m}}$. The values of the variogram ranges $r_{\mathrm{g}}$ and $r_{\mathrm{m}}$ are investigated between 25 and $1600 \mathrm{~m}$ with a discretization step equal to $25 \mathrm{~m}$. The underlying hypothesis is that the secondorder variogram reaches a sill before $1600 \mathrm{~m}$, which is the case for most images under study [14]. The parameter $\omega^{2}$ is defined within the interval $[0,1]$ with a discretization step of 0.01 . The variance $\sigma^{2}$ of $Z(x)$ is assumed to be known a priori and for the simplicity of the exposition it will not be retrieved as an image parameter. For the NDVI images under study, we will use the values of $\sigma^{2}$ which have been independently estimated from second-order variogram modeling by Garrigues et al. [14].

The estimation method consists in computing the least square criteria $\mathrm{Cr}$

$$
\mathrm{Cr}=\frac{1}{N_{d}} \sum_{i=1}^{N_{d}}\left(\gamma_{1, e}\left(h_{i}\right)-\gamma_{1}\left(h_{i}\right)\right)^{2}+\frac{1}{N_{d}} \sum_{i=1}^{N_{d}}\left(\gamma_{2, e}\left(h_{i}\right)-\gamma_{2}\left(h_{i}\right)\right)^{2}
$$

between the LUT elements $\left(\gamma_{1}(h)\right.$ and $\left.\gamma_{2}(h)\right)$ and the experimental variograms $\left(\gamma_{1, e}(h)\right.$ and $\left.\gamma_{2, e}(h)\right)$. The LUT is then ordered by increasing $\mathrm{Cr}$ values. The solutions, i.e., the estimated parameters $\omega_{\text {est }}^{2}, r_{\mathrm{g}, \text { est }}$, and $r_{\mathrm{m} \text {,est }}$, are defined as the mean of the $N_{s}$ first elements of the LUT. In this paper, $N_{s}$ is chosen equal to 1000 that corresponds to reasonable low $\mathrm{Cr}$ criteria [42], [43].

\section{RESULTS}

\section{A. Application on Simulated Images}

The estimation method presented in Section $\mathrm{V}$ is first applied to two images simulated from the random functions $Z_{1}(x)$ and $Z_{4}(x)$ with the following parameters: $r_{\mathrm{g}}=600 \mathrm{~m}, r_{\mathrm{m}}=$ $200 \mathrm{~m}, \omega_{1}^{2}=0.125$, and $\omega_{4}^{2}=0.5$. The estimated parameters for $Z_{1}(x)$ are $\omega_{\text {est }}^{2}=0.116 ; r_{\mathrm{g}, \text { est }}=697 \mathrm{~m} ; r_{\mathrm{m} \text {,est }}=235 \mathrm{~m}$. The estimated parameters for $Z_{4}(x)$ are $\omega_{\text {est }}^{2}=0.449 ; r_{\mathrm{g}, \text { est }}=$ $663 \mathrm{~m} ; r_{\mathrm{m} \text {,est }}=245 \mathrm{~m}$. Fig. 6 displays for $Z_{1}(x)$ and $Z_{4}(x)$ the experimental first- and second-order variograms computed over the simulated images, the theoretical first- and second-order variograms of the random function along with the first- and second-order variograms computed with the estimated parameters. Some discrepancies are observed between the estimated parameters $\omega_{\text {est }}^{2}, r_{\mathrm{g}, \text { est }}$, and $r_{\mathrm{m} \text {,est }}$ and the theoretical parameters $\omega^{2}, r_{\mathrm{g}}$, and $r_{\mathrm{m}}$ of the random functions $Z_{1}(x)$ and $Z_{4}(x)$. Since simulated images are single realizations of stochastic processes, differences are normally expected between the actual parameters used to generate the image and those estimated from the image. In addition, the discretization step used to compute the elements of the LUT limits the possible range of the retrieved parameter values and thus decreases the accuracy
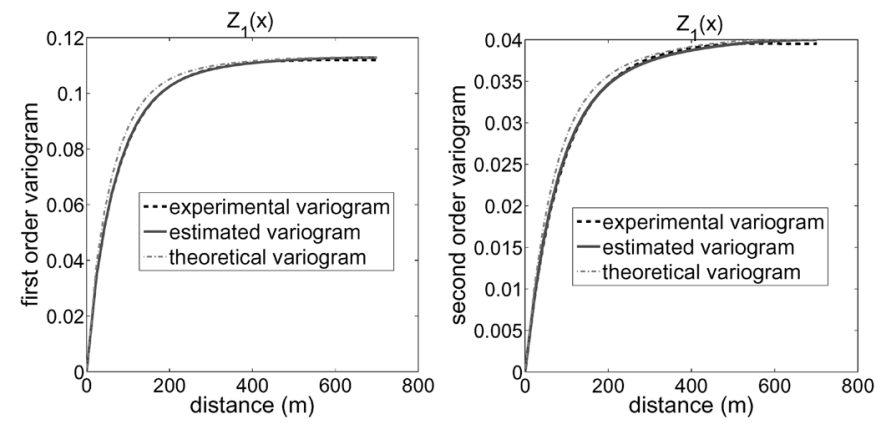

(a)
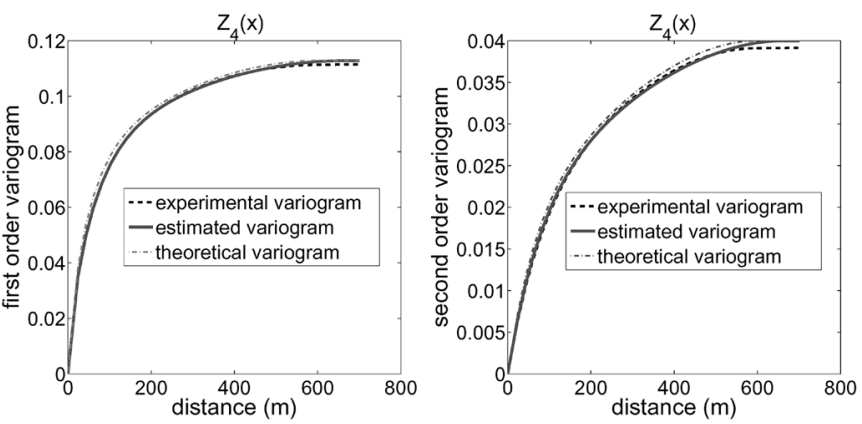

(b)

Fig. 6. Result of the estimation of the first and the second-order variograms from images simulated from (a) the random function $Z_{1}(x)\left(\omega_{1}^{2}=0.125\right)$ and (b) the random function $Z_{4}(x)\left(\omega_{4}^{2}=0.5\right)$ both defined by $r_{\mathrm{m}}=200 \mathrm{~m}$ and $r_{\mathrm{g}}=600 \mathrm{~m}$.

TABLE III

Parameters $\left(\omega_{\text {est }}^{2}, r_{\mathrm{g}, \text { est }}\right.$, AND $r_{\mathrm{m}, \mathrm{est}}$ ) Of THE Mixture Model $Z(x)$ ESTIMATED FROM EACH SPOT-HRV NDVI IMAGE. $\omega_{\text {est }}^{2}, r_{\text {g,est }}$, AND $r_{\text {m,est }}$ ARe the Multi-Gaussian Weight, the Multi-Gaussian RANGe, AND THE Mosaic RANGe, Respectively

\begin{tabular}{|l|l|l|l|}
\hline sites & $\omega_{\text {est }}^{2}$ & $r_{\text {g,est }}$ & $r_{\text {mest }}$ \\
\hline Fundulea01 & 0.0004 & $923 \mathrm{~m}$ & $915 \mathrm{~m}$ \\
\hline SudOuest02 & 0.07 & $837 \mathrm{~m}$ & $642 \mathrm{~m}$ \\
\hline Alpilles02 & 0.07 & $466 \mathrm{~m}$ & $375 \mathrm{~m}$ \\
\hline Jarvselja01 & 0.44 & $940 \mathrm{~m}$ & $571 \mathrm{~m}$ \\
\hline Nezer01 & 0.44 & $361 \mathrm{~m}$ & $1280 \mathrm{~m}$ \\
\hline Puechabon01 & 0.42 & $325 \mathrm{~m}$ & $1287 \mathrm{~m}$ \\
\hline
\end{tabular}

of the estimation. However, the objective of this paper is to describe the spatial structures observed within a given image. The accuracy of the estimation must thus be evaluated by the quality of the adjustment between the estimated and the experimental curves of the variogram. As displayed by Fig. 6, the adjustments are very accurate for the simulated images.

\section{B. Characterization on Landscape Images}

The approach is now applied to the actual NDVI images presented in Section II to characterize the spatial structures of the vegetation cover over distinct landscapes. Table III provides the parameters $\omega_{\text {est }}^{2}, r_{\mathrm{g}, \text { est }}$, and $r_{\mathrm{m} \text {,est }}$ estimated from each NDVI image. Results are analyzed per type of landscape as follows.

1) Crop Sites: Fig. 7 displays the experimental first- and second-order variograms computed over the NDVI images of 

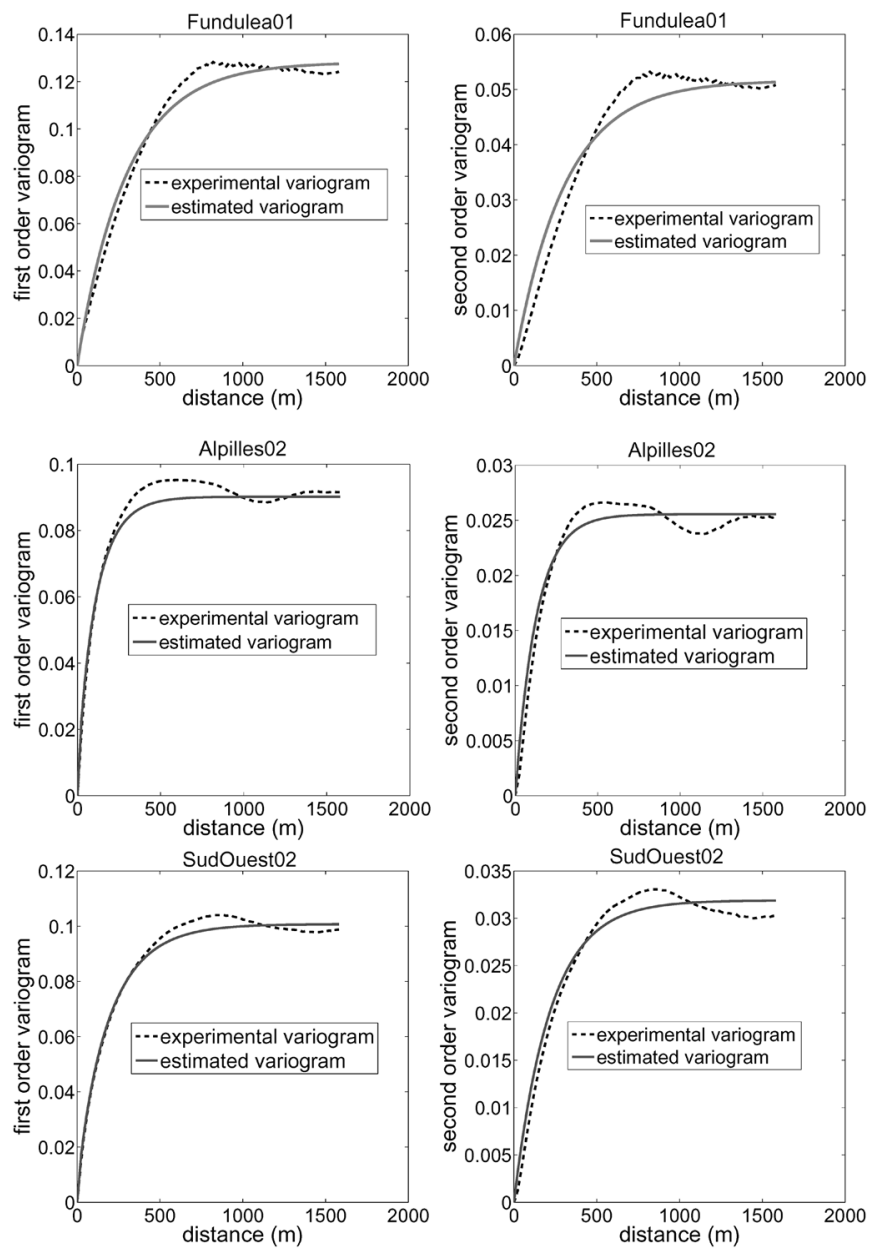

Fig. 7. Result of the estimation of the first- and the second-order variograms from the NDVI images of crop sites. Table III provides the parameters of the mixture model estimated from each NDVI image.

crop sites along with the first- and second-order variograms computed with the estimated parameters of the mixture model applied to these sites.

The fraction $\left(1-\omega^{2}\right)$ of the total image variance explained by the mosaic component of the mixture model $Z(x)$ is generally higher than that explained by the multi-Gaussian component $\left(\omega^{2}\right)$. It highlights the mosaic pattern of the agricultural fields which is mainly the result of anthropogenic processes (field shape and size, seedling and harvesting date, crop rotation,...). The range of the mosaic model $r_{\mathrm{m}}$ is generally related to the mean size of the fields. It varies from large fields (Fundulea01, $r_{\mathrm{m}}=915 \mathrm{~m}$ ) to small fields (Alpilles02, $\left.r_{\mathrm{m}}=375 \mathrm{~m}\right)$. However, the characterization of the field sizes by the variogram ranges is a nontrivial issue. Indeed, it may be disturbed by the gathering of fields with similar NDVI values which create larger apparent spatial structures (e.g., SudOuest02).

On Fundulea01 the mosaic component explains almost 100\% of the NDVI overall variability. As shown on Fig. 1(a), this site is characterized by a mosaic of bare soil fields with low NDVI values and mature crop fields with high NDVI values. The regular and strong discontinuities of NDVI between fields and the low NDVI variability within the fields explain that the
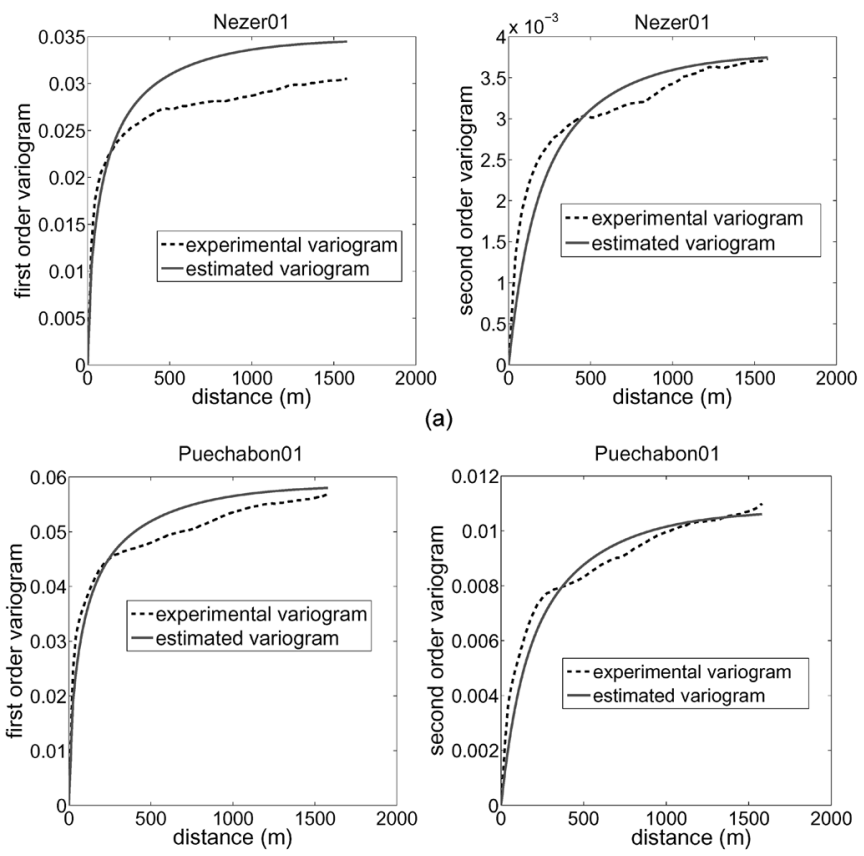

(b)
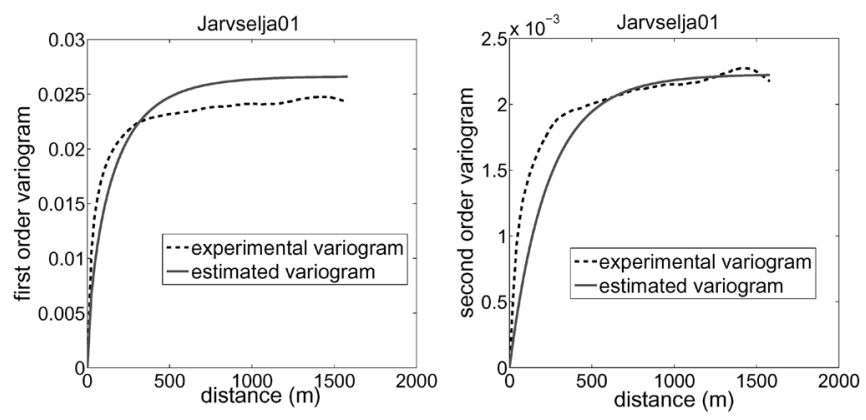

(c)

Fig. 8. Result of the estimation of the first and the second-order variograms from the NDVI images of natural vegetation and forest sites. Table III provides the parameters of the mixture model estimated from each NDVI image.

NDVI spatial structures of this site are accurately described by the Poisson lines of the mosaic model.

In contrast, on Alpilles02 and SudOuest02, the fraction of variance of the multi-Gaussian model $\omega^{2}$ is nonnull. It characterizes diffuse spatial structures associated with more continuous variation of NDVI than between crop fields. These spatial structures are caused by small variation of vegetation cover within forest and fallow area. However, these diffuse spatial structures explain a much lower NDVI variability $\left(\omega^{2}=0.07\right)$ than the mosaic of agricultural fields which is the main spatial structure of crop sites.

2) Natural Vegetation and Forest Sites: Fig. 8 displays the experimental first- and second-order variograms computed over the NDVI images of forest and natural vegetation sites along with the first- and second-order variograms computed with the estimated parameters of the mixture model applied to these sites.

The fraction of image variance explained by the multiGaussian model is generally larger on natural and forest vegetation sites ( $\omega^{2}$ close to 0.36 ) than on crop sites. It describes the fuzzy pattern of the vegetation cover associated with smoother 


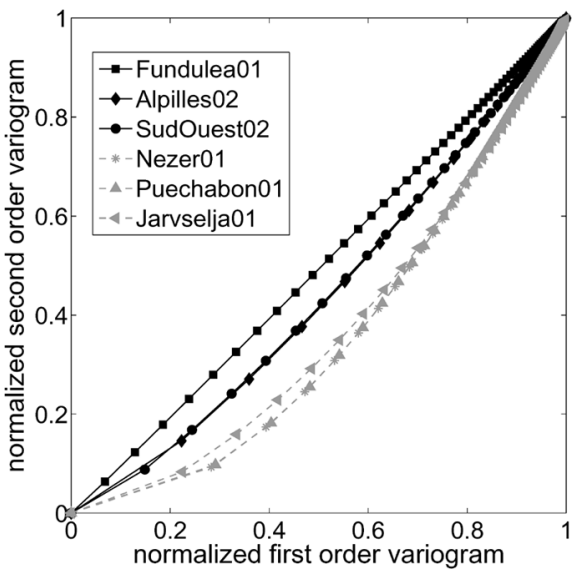

Fig. 9. Normalized first- and second-order variograms $\left(\gamma_{1}(h) ; \gamma_{2}(h)\right)$ computed with the parameters of the mixture model estimated from the NDVI images of the landscapes under study. The solid and black lines represent crop sites characterized by a high variance weight of the mosaic model, i.e., low $\omega^{2}$. The dash and gray lines correspond to natural vegetation and forest sites characterized by a higher variance weight $\omega^{2}$ of the multi-Gaussian model than on crop sites.

NDVI spatial continuity than observed over agricultural landscapes. These patterns correspond to various sources of NDVI variability, including the understory cover, the density, height and type of trees, and the presence of open areas. They are mainly generated by ecological processes (light availability, species competition,...) and environmental processes (presence of water, soil salinity, microtopography, geomorophologic factors,...).

However, the mosaic model still explains the major part of the overall NDVI variability over these sites. In agreement with results found on crop sites, it characterizes spatial structures generated by anthropogenic processes, including the rectangular field patterns of the forest plantation, the presence of roads or singular objects (quarry on Puechabon01).

These examples illustrate the potential of the mixture model to characterize the nature of the processes structuring the landscape. The mosaic model describes mosaic spatial structures associated with strong NDVI discontinuities generally generated by anthropogenic processes while the multi-Gaussian model shows evidence of diffuse spatial structures associated with continuous variation of NDVI engendered by ecological and environmental processes. This approach can thus be used to discriminate different types of landscape as shown by Fig. 9 which displays for each site under study, its normalized second-order variogram as a function of its normalized firstorder variogram both computed with the estimated parameters of the mixture model.

\section{ACCURACY OF The Estimation of the Mixture MOdel PARAMETERS}

The adjustment of the first- and second-order variogram curves and thus the estimation of the parameters $\omega_{\text {est }}^{2}, r_{\mathrm{g}, \text { est }}$, and $r_{\mathrm{m} \text {,est }}$ is less accurate on the actual NDVI images (Figs. 7 and 8) than on the simulated images (Fig. 6). This is particularly true on forest and natural vegetation sites.
The main reason is that the hypothesis on which the mixture model relies are only partly verified over actual images. For Nezer01 or Puechabon01, the experimental second-order variograms do not reach a stationary sill at the image scale. Thus, it implies that the second-order stationarity hypothesis characterizing the multi-Gaussian and mosaic random functions is not consistent with the data [14]. This is due to spatial structures extending beyond the image extent creating apparent trends in the image. Larger image size would be more appropriate on these sites to characterize their spatial structures.

In this paper, the images are considered as realizations of Gaussian random function. However, most investigated images have not Gaussian histogram. It is not trivial to relate this issue to the quality of the adjustment of the variogram curves. Further work is required to evaluate the impact of the non-Gaussian histogram of the images on the characterization of the image spatial structure by the mixture model.

Besides, within the class of mosaic models, Poisson lines may be not realistic enough to model the mosaic spatial structures observed in the landscape. This model was chosen because it was the only mosaic model for which the theoretical expressions of its first- and second-order variograms were available. Other mosaic models such as Voronoi polygons or nested lines model could also be considered but further work is required to establish the theoretical first-order variogram of these models.

The characteristics of the retrieval method also affect the accuracy of the estimation. We currently use a LUT method. Once the table is generated, this method is easy to implement, easy to use and fast enough. In addition, it leads to a global solution and avoids selecting a local minimum as it may be the case with other optimization system. However, the precision of the LUT method depends on the size of the table generated. Thus, results may vary with the discretization steps used to retrieve the parameters $\omega^{2}, r_{\mathrm{g}}$, and $r_{\mathrm{m}}$. In this paper, the finest discretization steps have been chosen given the available computing resources at the time of this paper. Additional work should evaluate whether finer discretization steps than those used in this paper increase the accuracy of the estimations.

Finally, the second-order variogram sill $\sigma^{2}$ is not retrieved by the LUT. It has been independently estimated from secondorder variogram modeling by Garrigues et al. [14]. This a priori value of $\sigma^{2}$ forces the adjustment of the second-order variogram sill. But it limits the possibilities for adjusting the sill of the first-order variogram for some sites (e.g., Jarvselja01). Thus, it should be included in the LUT parameters and it should be concurrently estimated with the others parameters of the mixture model.

\section{CONCLUSION}

This paper provides a new approach to characterize the spatial structures within remote sensing imagery using stochastic models and geostatistic metrics.

The second-order variogram has been widely used in previous studies to describe the spatial variations within remote sensing image. We demonstrated here that the information contained by the second-order variogram may not be sufficient 
to discriminate image spatial structures which are visually distinct. We introduced a new tool, the first-order variogram, which used in combination with the second-order variogram, demonstrated its efficiency to describe the image spatial structures.

We developed a method based on the simultaneous use of both first- and second-order variogram to characterize the image spatial structures. In this method, the image spatial structures are modeled as a weighted linear combination of two stochastic models: a Poisson line mosaic model and a multiGaussian model. The mosaic model is a tessellation model partitioning the image into nonoverlapping cells associated with constant and random value while the multi-Gaussian model generates diffuse and continuous variation in the image. The mosaic model is characterized by a linear relationship between the first- and second-order variograms, while the multiGaussian model is characterized by a quadratic relationship. This difference is the basis of the method for distinguishing between the multi-Gaussian and the mosaic model. Each (mosaic and multi-Gaussian) model describes one spatial structure within the image and is characterized by the range of its secondorder variogram and the fraction of the total image variance explained by the model. The model parameters are estimated from the experimental first- and second-order variograms computed over the image using a LUT. The retrieval method was validated on a set of simulated images showing its accuracy to estimate the model parameters.

Then, the method was applied to actual SPOT-HRV NDVI images extracted from the VALERI database in order to characterize the spatial structures of distinct landscapes. The mosaic model describes strong NDVI discontinuities in the image generally generated by anthropogenic processes such as the mosaic spatial structure of agricultural sites. In contrast, the multiGaussian model shows evidence of diffuse and continuous variation of NDVI engendered by ecological and environmental processes such as the fuzzy pattern observed over forest and natural vegetation sites.

Several points of the method proposed in this paper can be improved by further studies. For few landscapes, the $3000 \times$ $3000 \mathrm{~m}$ image size used in this paper was too small to encompass the extent of the landscape spatial structures. Further studies are needed to evaluate the required size of images. Regarding the LUT retrieval method, a finer sampling of the parameter ranges should be used to increase the accuracy of the estimations. The total image variance should also be concurrently estimated with the other parameters to avoid forcing the adjustment of the variogram sills. Regarding the model hypothesis, since most of the NDVI images under study have not Gaussian histogram, other probability distribution functions than the Gaussian distribution used in this paper should be tested. In addition, other types of mosaic models (e.g., Voronoi polygons or nested lines model) should also be considered to provide more realistic description of the landscape spatial structures than that given by the Poisson line mosaic model.

Finally, the approach provided in this paper is powerful to characterize the nature of the processes structuring the landscape that is promising for a range of applications. The main finding of this paper is that the mosaic model is an indicator of anthropogenic processes and the multi-Gaussian model describes environmental and ecological processes. This result can thus be used as an indicator of change of land surface type to monitor the anthropogenic effects on the landscape such as the conversion of natural vegetation area into agricultural area. However, this result is limited by the number, the type, the low complexity, and the small size of the landscapes analyzed. A more representative sampling of landscape types is required to refine this conclusion. In particular, it would be interesting to test if natural landscapes which have not been affected by human activities are characterized by a large variance weight of the multi-Gaussian model. Further works should also consider larger area and more complex landscapes in terms of different types of vegetation, land use, topography features, and soil properties.

\section{REFERENCES}

[1] P. J. Sellers, "Modeling the exchange of energy, water, and carbon between continents and atmosphere," Science, vol. 275, no. 5299, pp. 602-609, Jan. 1997.

[2] R. A. Pielke and R. Avissar, "Influence of landscape structure on local and regional climate," Landsc. Ecol., vol. 4, no. 2/3, pp. 133-155, 1990.

[3] T. J. Lyons and S. Halldin, "Surface heterogeneity and the spatial variation of fluxes," Agric. For. Meteorol., vol. 121, no. 3/4, pp. 153-165, Feb. 2004.

[4] D. O. Hipps and C. M. U. Neale, "Spatial structure and scaling of surface fluxes in a Great Basin ecosystem," in Scaling Up in Hydrology Using Remote Sensing, J. B. Stewart, E. T. Engman, R. A. Feddes, and Y. Kerr, Eds. Chichester, U.K.: Wiley, 1996, pp. 113-124.

[5] O. Wendroth, W. Pohl, S. Koszinski, H. Rogasik, C. J. Ritsem, and D. R. Nielsen, "Spatio-temporal patterns and covariance structures of soil water status in two Northeast-German field sites," J. Hydrol., vol. 215, no. 1, pp. 38-58, Feb. 1999.

[6] F. Csillag and S. Kabos, "Wavelets, boundaries and the analysis of landscape pattern," Ecoscience, vol. 9, no. 2, pp. 177-190, 2002.

[7] D. E. Ahl, S. T. Gower, D. S. Mackay, S. N. Burrows, J. M. Norman, and G. R. Diak, "Heterogeneity of light use efficiency in a northern Wisconsin forest: Implications for modeling net primary production with remote sensing," Remote Sens. Environ., vol. 93, no. 1/2, pp. 168-178, Oct. 2004.

[8] D. S. Schimel, F. W. Davis, and T. G. F. Kittel, "Spatial information for extrapolation of canopy processes: Examples from FIFE," in Scaling Physiological Processes. Leaf to Globe, J. R. Ehleringer and C. B. Field, Eds. New York: Academic, 1993, pp. 21-29.

[9] J. Pellenq, J. Kalma, G. Boulet, G.-M. Saulnier, S. Wooldridge, Y. Kerr, and A. Chehbouni, "A disaggregation scheme for soil moisture based on topography and soil depth," J. Hydrol., vol. 276, no. 1-4, pp. 112-127, May 2003.

[10] S. Garrigues, D. Allard, and F. Baret, "Influence of the spatial heterogeneity on the non linear estimation of leaf area index from moderate resolution remote sensing data," Remote Sens. Environ., vol. 106, pp. 286298, 2006.

[11] G. B. M. Heuvelink and E. J. Pebesma, "Spatial aggregation and soil process modelling," Geoderma, vol. 89, no. 1, pp. 47-65, Apr. 1999.

[12] R. Faivre and A. Fischer, "Predicting crop reflectances using satellite data observing mixed pixels," J. Agric., Biol., Environ. Stat., vol. 2, no. 1, pp. 87-107, 1997.

[13] O. Merlin, G. Chehbouni, Y. Kerr, E. Njoku, and D. Entekhabi, "A combined modeling and multi-spectral/multi-resolution remote sensing approach for disaggregation of surface soil moisture: Application to SMOS configuration," IEEE Trans. Geosci. Remote Sens., vol. 43, no. 9, pp. 2036-2050, Sep. 2005

[14] S. Garrigues, D. Allard, F. Baret, and M. Weiss, "Quantifying spatial heterogeneity at the landscape scale using variogram models," Remote Sens. Environ., vol. 103, no. 1, pp. 81-96, Jul. 2006.

[15] D. L. B. Jupp, A. H. Strahler, and C. E. Woodcock, "Autocorrelation and regularization in digital images I: Basic theory," IEEE Trans. Geosci. Remote Sens., vol. 26, no. 4, pp. 463-473, Jul. 1988.

[16] R. D. Jackson, "Spectral indices in n-space," Remote Sens. Environ., vol. 13, no. 5, pp. 409-421, Nov. 1983.

[17] M. F. P. Bierkens, P. A. Finke, and P. De Willigen, Upscaling and Downscaling Methods for Environmental Research. Dordrecht, The Netherlands: Kluwer, 2000, p. 204. 
[18] C. Cao and N. S. Lam, "Understanding the scale and resolution effects in remote sensing and GIS," in Scale in Remote Sensing and GIS, D. A. Quattrochi and M. F. Goodchild, Eds. Boca Raton, FL: Lewis Publishers, 1997, pp. 57-72.

[19] L. Bian, "Multiscale nature of spatial data in scaling up environmental models," in Scale in Remote Sensing and GIS, D. A. Quattrochi and M. F. Goodchild, Eds. Boca Raton, FL: Lewis Publishers, 1997, pp. 13-27.

[20] Y. Tian, C. E. Woodcock, Y. Wang, J. L. Privette, N. V. Shabanov, L. Zhou, Y. Zhang, W. Buermann, J. Dong, B. Veikkanen, T. Häme, K. Andersson, M. Ozdogan, Y. Knyazikhin, and R. B. Myneni, "Multiscale analysis and validation of the MODIS LAI product. II. Sampling strategy," Remote Sens. Environ., vol. 83, no. 3, pp. 431-441, Dec. 2002.

[21] B. Julesz, "Visual pattern discrimination," IRE Trans. Inf. Theory, vol. 8, no. 2, pp. 84-92, Feb. 1962.

[22] A. Gagalowicz, "Vers un modèle de textures," Ph.D. dissertation, Université Pierre et Marie Curie, Paris VI, Paris, France, 1983.

[23] R. M. Haralick and K. S. Shanmugan, "Combined spectral and spatial processing of ERTS imagery data," Remote Sens. Environ., vol. 3, no. 1, pp. 3-13, 1974.

[24] L. De Cola, "Multifractals in image processing and processing imaging," in Fractals in Geography, N. S.-N. Lam and L. De Cola, Eds. Englewood Cliffs, NJ: Prentice-Hall, 1993, pp. 282-304.

[25] Z. Hu, Y. Chen, and S. Islam, "Multiscaling properties of soil moisture images and decomposition of large and small scale features using wavelet transforms," Int. J. Remote Sens., vol. 19, no. 13, pp. 2451-2467, 1998.

[26] S. Lovejoy, D. Schertzer, Y. Tessier, and H. Gaonac'h, "Multifractals and resolution-independent remote sensing algorithms: The example of ocean colour," Int. J. Remote Sens., vol. 22, no. 7, pp. 1191-1234, May 2001.

[27] L. De Cola, "Fractal analysis of a classified Landsat scene," Photogramm. Eng. Remote Sens., vol. 55, no. 5, pp. 601-610, 1989.

[28] B. B. Mandelbrot, The Fractal Geometry of Nature. New York: Freeman, 1983.

[29] M. H. Cosh and W. Brutsaert, "Microscale structural aspects of vegetation density variability," J. Hydrol., vol. 276, no. 1-4, pp. 128-136, May 2003.

[30] S. Mallat, A Wavelet Tour of Signal Processing. San Diego, CA: Academic, 1999.

[31] P. M. Atkinson, "Geostatistical regularization in remote sensing," in Modelling Scale in Geographic Information Science, N. J. Tate and P. M. Atkinson, Eds. New York: Wiley, 2001, pp. 237-260.

[32] J.-P. Chilès and P. Delfiner, Geostatistics: Modeling Spatial Uncertainy. New York: Wiley-Interscience, 1999.

[33] P. J. Curran, "The semivariogram in remote sensing: An introduction," Remote Sens. Environ., vol. 24, no. 3, pp. 493-507, Apr. 1988.

[34] B. Lacaze, S. Rambal, and T. Winkel, "Identifying spatial patterns of Mediterranean landscapes from geostatistical analysis of remotely-sensed data," Int. J. Remote Sens., vol. 15, no. 12, pp. 2437-2450, 1994.

[35] C. E. Woodcock, A. H. Strahler, and D. L. B. Jupp, "The use of variograms in remote sensing: A/ scene models and simulated images," Remote Sens. Environ., vol. 25, no. 3, pp. 323-348, Aug. 1988.

[36] D. L. B. Jupp, A. H. Strahler, and C. E. Woodcock, "Autocorrelation and regularization in digital images II: Simple image models," IEEE Trans. Geosci. Remote Sens., vol. 27, no. 3, pp. 247-258, 1988.

[37] C. E. Woodcock, A. H. Strahler, and D. L. B. Jupp, "The use of variograms in remote sensing: B/ Real digital images," Remote Sens. Environ., vol. 25, no. 3, pp. 349-379, Aug. 1988.

[38] F. Baret, M. Weiss, D. Allard, S. Garrigues, M. Leroy, H. Jeanjean, R. Fernandes, R. B. Myneni, J. T. Morissette, J. Privette, H. Bohbot, R. Bosseno, G. Dedieu, C. Di Bella, M. Espana, V. Gond, X. F. Gu, D. Guyon, C. Lelong, P. Maisongrande, E. Mougin, T. Nilson, F. Veroustraete, and R. Vintilla, "VALERI: A network of sites and a methodology for the validation of medium spatial resolution land satellite product," Remote Sens. Environ., to be published.

[39] H. Wackernagel, Multivariate Geostatistics: An Introduction With Applications. Berlin, Germany: Springer-Verlag, 2003.
[40] J. P. Chilès and D. Allard, "Stochastics simulations of soil variations," in Environmental Soil-Landscape Modeling, S. Grunwald, Ed. Boca Raton, FL: CRC Press, 2005, p. 496.

[41] C. Lantuéjoul, Geostatistical Simulation: Models and Algorithms. Berlin, Germany: Springer-Verlag, 2002.

[42] Y. Knyazikhin, J. V. Martonchik, R. B. Myneni, D. J. Diner, and S. W. Running, "Synergistic algorithm for estimating vegetation canopy leaf area index and fraction of absorbed photosynthetically active radiation from MODIS and MISR data," J. Geophys. Res., vol. 103, no. D24, pp. 32 257-32 275, 1998.

[43] M. Weiss, F. Baret, R. B. Myneni, A. Pragnère, and Y. Knyazikhin, "Investigation of a model inversion technique to estimate canopy biophysical variables from spectral and directional reflectance data," Agronomie, vol. 20, pp. 3-22, 2000. DOI: 10.1051/agro:2000105.

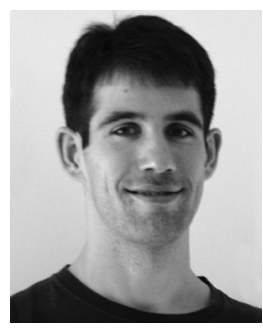

Sébastien Garrigues received the Ph.D. degree in remote sensing and geostatistic, performed at INRA, Avignon, France, from the Ecole Nationale Supérieure Agronomique de Rennes, France, in 2004.

He is currently a Research Associate of the Earth System Science Interdisciplinary Center, University of Maryland, College Park, working at the NASA Goddard Space Flight Center, Greenbelt, MD. His main research interests include geostatistical modeling of spatial heterogeneity from remote sensing data and the validation of the land surface products (LAI, Fapar, Albedo) within the framework of the Land Product Validation subgroup of the Committee on Earth Observing Satellites.

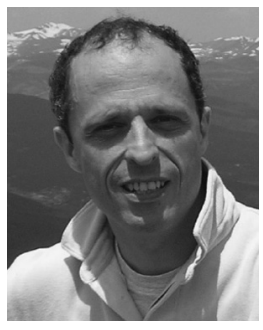

Denis Allard received the Ph.D. degree in geostatistics from the Ecole des Mines de Paris, Paris, France.

He was a Visiting Assistant Professor at the Department of Statistics, University of Washington, Seattle, and is currently a Senior Researcher at the Biostatistics and Spatial Processes Unit in Avignon, France, part of the Applied Mathematics and Informatics Department of the French National Institute for Agricultural Research. His research interests are in the statistical modeling and analysis of spatial data with emphasis on environmental and ecological applications.

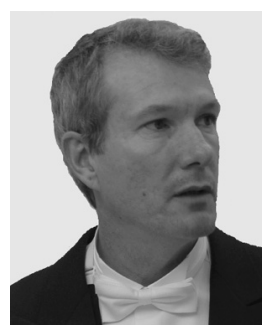

Frédéric Baret received the Ph.D. degree, focusing on the application of remote sensing to agriculture, in 1986.

Since that time, he has been working at the National Institute of Agronomical Research, Avignon, France, focusing on radiative transfer modeling in the solar domain, estimates of canopy and soil characteristics from radiometric observations, and assimilating these data into canopy functioning models. He was also coordinating large experiments such as Alpilles-ReSeDA, ADAM, and is currently in charge of the VALERI and CYCLOPES projects for the development and validation of medium resolution satellite products. 